\title{
Future e-government research: 13 research themes identified in the eGovRTD2020 project
}

\author{
Maria Wimmer \\ University of Koblenz-Landau, \\ Institute for IS Research, \\ Research Group \\ eGovernment, \\ Universitaetsstr. 1, 56070 \\ Koblenz, Germany, \\ wimmer@uni-koblenz.de
}

\author{
Cristiano Codagnone \\ Political Science Faculty of \\ Milan State University, Milan, \\ Italy \\ cristiano.codagnone@unimi.it
}

\author{
Marijn Janssen \\ School of Technology, \\ Policy and Management, \\ Delft University of \\ Technology, \\ Jaffalaan 5, NL-2600 GA, \\ Delft, The Netherlands, \\ m.f.w.h.a.janssen@tudelft.nl
}

\begin{abstract}
E-government research has become a recognized research domain and many policies and strategies are formulated for e-government implementations. Most of these target the next few years and limited attention has been giving to the long term. The eGovRTD2020, a European Commission co-funded project, investigated the future research on e-government driven by changing circumstances and the evolution of technology. This project consists of an analysis of the state of play, a scenario-building, a gap analysis and a roadmapping activity.

In this paper the roadmapping methodology fitting the unique characteristics of the e-government field is presented and the results are briefly discussed. The use of this methodology has resulted in the identification of a large number of e-government research themes. It was found that a roadmapping methodology should match the unique characteristics of e-government. The research shows the need of multidisciplinary research.
\end{abstract}

\section{Introduction}

Today, e-government has become a recognized research domain, as well as an established public policy area worldwide, including the EU and Member States levels. A modernized ICT-enabled government is acknowledged as a key condition in promoting the growth and competitiveness of the European knowledge society. When considered as a single entity, government is by far Europe's biggest economic sector: overall government spending across EU-15 amounted to about $49 \%$ of GDP in 2003 [6] and affects all other sectors of the economy. Given this sheer size, it is increasingly evident that governmental efficiency results in important performance improvements and cost savings. Similarly, an increase in the efficiency and effectiveness of public sector management of the economy and society substantially reduces the administrative burden government imposes on businesses and citizens, which in European countries is particularly high. The first OECD study conducted in 2001 on this topic showed that the average cost of this burden on only the business branch in Europe is equal to $2 \%$ of GDP, and can reach as high as to $7 \%$ [12]. Not surprisingly, scenarios presented within the EUfinanced study eGEP (funded under the MODINIS program, see [1] [3]) predicted that between 2005 and 2010 e-government research and implementation programs could boost EU's aggregated GDP by $1.54 \%$, or by 166 billion Euros [5].

Given the strategic importance of e-government, many EU Member States have adopted their existing strategies for public sector modernization and transformation of e-government to achieve some of the mentioned promises and to meet the objectives of EU strategies such as i2010 [7] and the Lisbon Strategy [8]. However in most cases, these strategies and activities are only short- to mid-term oriented and do not fully take into account some of the critical issues that, if addressed through research, can become key enabling success factors. If overlooked, these issues will remain barriers preventing realization of the promise of e-government. As a result, there is a need for a methodology investigating the long-term and taking the ambition of the government into account.

There is an increasingly urgent need to facilitate open discussion about the future strategic development of e-government and the public sector among European and worldwide experts. The goal of such a discussion is to transform the European Government landscape into a coherent community, capable of anticipating customer needs and of making use of the available potentials of innovative ICT. Current deficiencies and challenges of e-government research 
in respect to potential futures of Governments, Society and ICT in 10 years and beyond must be identified and carefully investigated.

On the basis of such challenges, the European Commission funded a specific support action to identify the needs of the future and to develop a streamlined research roadmap for e-government. eGovRTD2020 was carried out in the period of January 2006 till May 2007. Results of the first phases of the project have been reported in a number of publications (e.g. [4][10][20]). In this paper, we focus on the research roadmap and present the methodology as well as the research themes identified. We further discuss how these research themes address the strategic objectives of the EC. In the conclusions we reflect on the achievements of the project in the light of impact and necessities.

This paper is structured as follows. First we reflect roadmapping methodologies and introduce the eGovRTD2020 roadmap method. Thereafter, the thirteen research themes elaborated in the project are introduced. Finally, we reflect on the level of participation in the process by different experts and provide some concluding reflections on the impact of the results in future programs of research.

\section{2. eGovRTD2020 roadmapping method}

The overall aim of eGovRTD2020 was to identify and characterize the key research challenges, required constituency, and possible implementation models for holistic and dynamic governments in Europe and around the world in 2020 and beyond. Based on a number of scenarios [10][11] and the elicitation of gaps between needs of research emerging in the scenarios and current research [15], research themes have been developed (see section 3) based on a systemically and structured roadmap methodology.

Technology Roadmapping (TRM) is a strategic planning approach to identify future research needs by providing a means of depicting the link between the current, emerging and potential technologies and the long term market opportunities to which it could apply them [20]. TRM are used by companies to support their long term strategy and identify research and development needs.

TRMs look very simple in terms of description formats, but their development poses significant challenges and is not easy [13]. The term 'roadmap' refers to the main purpose of the roadmapping approach, namely to chart an overall direction for technology development or usage [9]. A standard methodology for technology roadmapping covering all kinds of situations does not exist [13]. Furthermore,
TRM for government requires balancing the application and extension of existing technology and the generation of new technology innovations.

A holistic approach to futures research is applied in policy-oriented science and technology roadmapping like it was developed for the eGovRTD2020 project. The reason for specifically developing a roadmap methodology for e-government futures research was that e-government is formed by unique characteristics which require consideration of the complexity and broad range of issues to be born in mind.

By its very nature, e-government involves many organizations and is a complex and multidisciplinary domain [17]. The field of e-government involves the interactions and reciprocal conditioning of several different systems which cannot be treated as a simple industry and even less as a product. The democratic systems of countries and participation in constituents' policy-making processes play a major role in creating e-government. Accordingly, any e-government roadmapping approach needs to address a broad range of societal, organizational and cultural challenges, and cannot be limited to only technological considerations. Instead, it goes one step further than including fundamental and core scientific research.

When roadmapping e-government research programs, the focus of the TRM can neither be on a single technical product nor on a single industry. It must be based on a holistic look at public administration, which should be viewed as a dynamic and open socio-technical system. This means that a comprehensive approach must take into consideration technological developments and the corresponding industries, whilst also investigating the broad sociocultural and socio-economic trends, including in-depth analysis of the demand side as well as of the practitioners' side. The demand side includes users' needs, political ambitions which might change over time, resistance, cultural barriers and differences. The practitioners side aims at analyzing political, institutional and regulatory dimensions - cf. e.g. holistic approach [16][17]). Therefore, policy-oriented science and technology roadmaps differ from corporate or industry TRM in the following ways.

a) The scope is on dealing with societal 'challenges' rather than a technological product or industry per se; hence

b) The domain under consideration is larger, as it must move further upstream beyond technological developments into fundamental scientific multidisciplinary research covering technological, social, cultural, political, legal aspects in order to envisage the potential future applications; and

c) To optimize public R\&D investments and ensure their relevance to society they must encompass the 
economic, political and social dimensions, and the complex interactions between them.

A more detailed comparison of such technology roadmapping methodologies is given in [20].

The eGovRTD2020 roadmapping captures the societal challenges by including the scenario-building, followed by a gap analysis. Its goal is to identify the necessary transition steps to reach the visions of egovernment in 2020, involving research, development and implementation. More specifically, key research themes and respective concerted research actions were defined on the basis of a common understanding of visionary desired images of future government activities, as well as of challenges and deficiencies of current research. Based on this roadmap, targeted actors in the field of e-government in Europe and worldwide shall be facilitated and supported to take action to advance the field.

To better identify the needed research themes and internal implementation models for effectively addressing and resolving research gaps in egovernment, the comprehensive roadmapping methodology as schematically shown in figure 1 was developed by the partners of the eGovRTD2020 consortium.

The methodology comprises our main activities, which should ensure that the unique characteristics of a POS\&TRM approach are taken into account.

a) Regional workshop with experts from governments, ICT industry and consulting, and academia, and an online consultation to reach
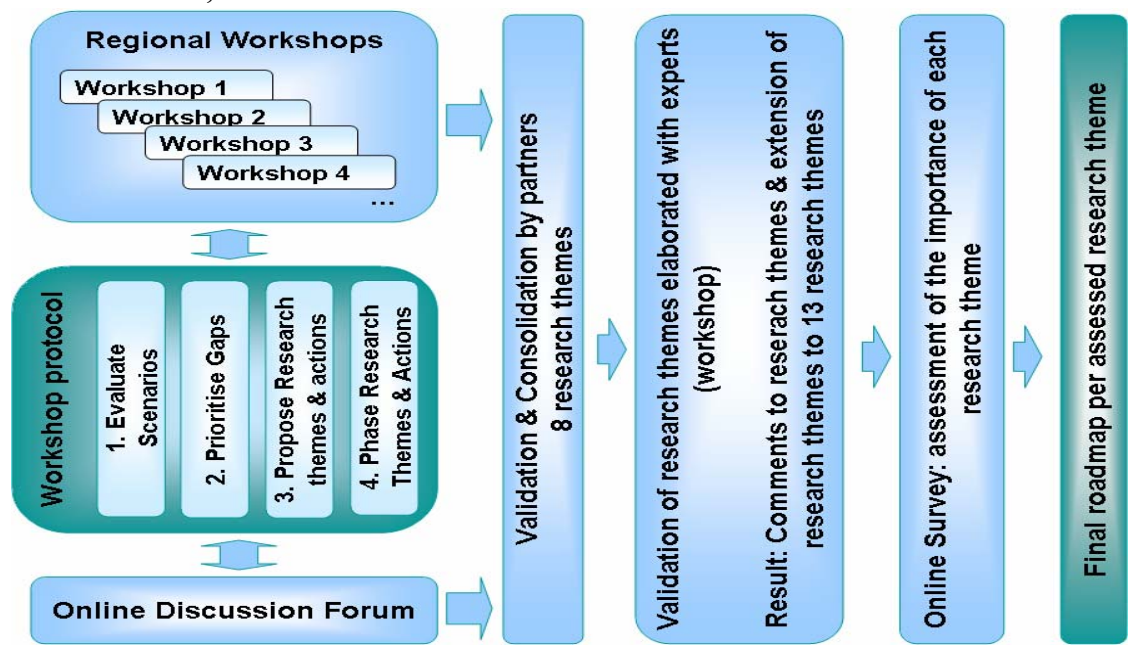

Figure 1: Overall eGovRTD2020 roadmapping methodology [18]

beyond the regional scale. The regional workshops are aimed at capturing a variety of societal challenges happening in various EU countries as well as world-wide. The aim of this activity was to assess the scenarios and gaps identified, and to define key research themes for e-government, including indication of actions and actors to implement the research, as well as a time-frame.

b) Validate and consolidate the inputs from the regional workshops and the online consultancy towards a research roadmap for e-government.

c) Expose the condensed research themes extracted from the regional workshops and online forum to a wider group of experts through a focused consultation workshop, and integrate the inputs gained thereby to the e-government research roadmap. This step should help to generalize the findings for a larger audience than is possible in workshops.

d) Assess the importance of the research themes by a larger audience via an online survey, and prioritize the themes.

The two main research instruments used in the course of the eGovRTD2020 roadmapping exercise were workshops and an online consultation tool. The workshops were aimed at a smaller audience and enabled in-depth interactions stimulating creativity, whereas the online consultation aimed at targeting a larger audience and involving representatives from all countries.

The main aims and protocol of the regional workshops and the online consultation were to:

1. Assess and comment on the final eight scenarios. The aim of this step was to validate the descriptions and comprehensiveness of the final eight scenarios by the experts in order to convey the most important aspects of potential futures of government activities in 2020.

2. Assess and prioritize the identified gaps. The participants were asked to assess the identified gaps in order to confirm validity of the assessment of highly relevant and important gaps performed by the project partners in the gap analysis.

3. Identify and develop research themes and actions. Group discussions in the regional workshops and an online discussion forum were used to develop important themes for future research in egovernment. The groups were formed based on the 
interest and expertise of the workshop participants. Each group was given a limited scope of consideration (ICT in governments, Government modernization, and Interaction with the constituency and environment). For the most important research themes, research actions and means of implementing the actions were formulated for target stakeholders.

4. Phasing the proposed research themes and actions. The proposed research actions were phased into a time scale of short-term (2006-2010), medium term (2011-2015) and long term (2016-2020) implementation.

The results gathered per workshop were used to improve the validity of former results. In this way an iterative and evolutionary approach was used to conduct the series of regional roadmapping workshops. Using the experiences from and feedback gained in each workshop, the materials and approach for the next rounds of roadmapping workshops were updated.

Based on the inputs of the regional workshops and the online consultation, the project consortium members synthesized and consolidated the results by extracting and working out a detailed set of eight research themes, including the actions and measures needed. These results were exposed to experts in tow ways. Via a) a validation workshop aimed at involving the participants and stimulating interaction and b) an online survey to assess the importance of each research theme and to target a larger audience. Again, this was done in an iterative and evolutionary way.

The results of the various activities along the roadmapping phase of eGovRTD2020 are documented in [18][19][20]. Thereby, a template was developed to ensure that each theme was described in a coherent and consistent manner. The template included a description of the research theme, the actions to take, the actors addressed and the time-span in which actions should be addressed. The template comprised three specific elements:

1. A detailed textual description of the research theme, including the following elements:

- An appealing title of the research theme;

- A brief abstract of the research theme, including the motivation of its relevance;

- Three keywords characterizing the main elements of the research theme;

- Key research questions that should be answered in the research theme;

(see section 3);

2. A description of the research actions, the means of actions, key actors and timeframe of action. An example of this part of the template is shown in table 1 ; and

3. A roadmap chart indicating per research theme the actions in a time-scale. An example of this part of a research them is depicted in Figure 2.

Table 1: Roadmap table with actions, means, and actors for research themes for the research theme: Trust in e-government [19]

\begin{tabular}{|l|l|l|l|}
\hline$\#$ & Description & Means & Actors \\
\hline 1 & $\begin{array}{l}\text { Studies to investigate a proper understanding of trust in e-government, } \\
\text { including: } \\
\text { What is trust, and how to create trust? } \\
\text { The differences among key trust relationships in C2G, B2G, G2G } \\
\text { What kind of trust impacts e-government? E.g. trust in government, } \\
\text { trust in ICT, trust in jurisdiction, execution and legislation } \\
\text { To what degree trust is needed in order to offer sophisticated } \\
\text { eServices? }\end{array}$ & $\begin{array}{l}\text { Action research, } \\
\text { analysis, desk } \\
\text { research }\end{array}$ & $\begin{array}{l}\text { Research with } \\
\text { key players from } \\
\text { governments } \\
\text { with some } \\
\text { support of ICT } \\
\text { industry \& } \\
\text { consulting }\end{array}$ \\
\hline 2 & $\begin{array}{l}\text { Develop a framework of mechanisms for monitoring trust between } \\
\text { governments and citizens, including: } \\
\text { Can ICT enable fair behavior? } \\
\text { What kind of behavior is acceptable? } \\
\text { How to prevent unfairness? }\end{array}$ & $\begin{array}{l}\text { Action research, gap } \\
\text { analysis }\end{array}$ & $\begin{array}{l}\text { Governments, } \\
\text { research and } \\
\text { consulting }\end{array}$ \\
\hline 3 & $\begin{array}{l}\text { Assessment of the risks of a trust framework for e-government, thereby } \\
\text { identifying both the potential threats and the level of distrust which can be } \\
\text { tolerated }\end{array}$ & Action Research & $\begin{array}{l}\text { Research, } \\
\text { consulting, } \\
\text { governments }\end{array}$ \\
\hline 4 & $\begin{array}{l}\text { Develop a legal basis for implementing a fully trusted e-government } \\
\text { framework }\end{array}$ & $\begin{array}{l}\text { Governments, } \\
\text { Consulting, } \\
\text { Research }\end{array}$ \\
\hline
\end{tabular}




\begin{tabular}{|l|l|l|l|}
\cline { 2 - 4 } & $\begin{array}{l}\text { Analysis of costs and benefits for fostering increased trust in e-government, } \\
\text { as well as identifying the investments needed to implement a trusted e- } \\
\text { government framework }\end{array}$ & $\begin{array}{l}\text { Desk research, } \\
\text { Comparative Analysis, } \\
\text { Impact analysis, Action } \\
\text { Research, Case stud. }\end{array}$ & $\begin{array}{l}\text { Research and } \\
\text { consulting with } \\
\text { key players from } \\
\text { governments }\end{array}$ \\
\hline 6 & $\begin{array}{l}\text { Apply the framework of "fair behavior" } \\
\text { Reengineering (rationalization) of old procedures and rules } \\
\text { Pilot cases } \\
\text { Benchmarking at micro-level } \\
\text { Benchmarking across countries (macro-level) }\end{array}$ & $\begin{array}{l}\text { Pilot projects, } \\
\text { Reengineering the } \\
\text { conceptual design, } \\
\text { Benchmarks }\end{array}$ & $\begin{array}{l}\text { Governments, } \\
\text { consulting }\end{array}$ \\
\hline 7 & $\begin{array}{l}\text { Development of an international model (Pan-European model) of trusted e- } \\
\text { government }\end{array}$ & Conceptual design & $\begin{array}{l}\text { Governments, } \\
\text { research, } \\
\text { consulting and } \\
\text { key players from } \\
\text { ICT industry }\end{array}$ \\
\hline
\end{tabular}

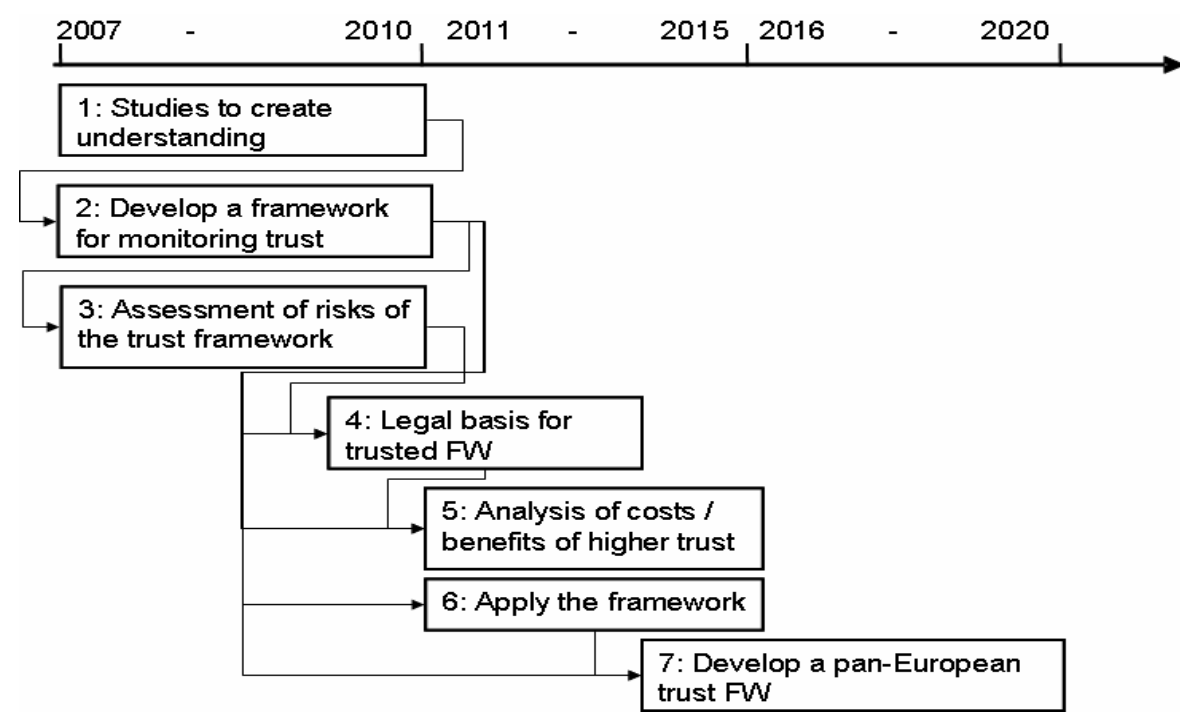

Figure 2: Example roadmap chart for trust in e-government (cf. [19])

The final eGovRTD2020 roadmap suggests thirteen research themes, each with a number of activities and actors as indicated in table 1 and Figure 2. In the next section, we briefly outline each research theme by providing an abstract and the main research questions. A full description of each research theme is provided in [19].

\section{Thirteen themes for future e- government research}

Trust in e-government: Trust is a fundamental element in all aspects of governments, including egovernment. The processes by which trust is built, destroyed, used, or abused are poorly understood and particular?

differ from one culture to another. Research is needed to understand what conditions are necessary and what mechanisms are needed to build and maintain trust in egovernment processes and services. In this respect there is also a need to identify the different kinds of trust related to e-government, e.g. trust in government or trust in ICT, and its special characteristics.

Key research questions are:

- What is trust, and how might trust be created?

- How to increase and secure trust in government in general and in e-government in

- How do trust relationships impact the take-up of e-government offers, also in different cultural environments?

Semantic and cultural interoperability of public services: Globalization and population movements are making societies increasingly multicultural. In principle, increased Internet access and the potential of the web for communication and education should bridge cultural boundaries. Yet, cultural and language differences continue to block effective communication and action across different countries, lobbies, and governmental functions. To facilitate cross-organizational collaboration among the various 
users, semantic and cultural interoperability are preconditions.

Key research questions:

- How might semantics, ontologies, or other approaches address and resolve challenges in cultural interoperability? How can information systems be modeled and designed, which embody semantic and cultural interoperability?

- How might consistent public services be provided across cultures and languages?

- How can ethnographic and cultural studies support the development and implementation of semantic and cultural interoperability in public administration?

- How can a shared understanding and seamless interoperability of public service design be created among different cultures and communities?

- What are the key criteria of semantic and cultural interoperability, which span across specific domains of governments and reflect e.g. the Schengen Agreement ${ }^{l}$ ?

Information quality: Governments, the market, and individuals increasingly need well-defined, timely, accurate, reliable and appropriate information drawn from many sources. In the future, guaranteeing information quality will become both more important and more difficult as the number and variety information sources (including informal sources such as wikis and weblogs) continues to grow.

Key research questions:

- What mechanisms are needed to find, select, evaluate, and authenticate information that is appropriate for a given use [automatically]? How to assess trustworthiness of certain information sources [automatically]?

- How to ensure trust and proper use of information in government decision-making?

- How to certify information sources thereby assuring a certain information quality? What metrics need to be applied?

- What kind of framework is needed to ensure information quality and trustworthy certification mechanisms?

- Which roles do governments fulfill in social webs and in guaranteeing the quality of decisionmaking?

- How to generate incentives for creating higher quality of information?

- How to engage social networks for ensuring information quality?

\footnotetext{
${ }^{I}$ http://eur-lex.europa.eu/LexUriServ/site/en/oj/2000/1_239/

1_23920000922en00010473.pdf
}

Assessing the value of government ICT investments: After years of substantial investments of public funds, the potential benefits of egovernment can no longer be assumed, but must be demonstrated. Proper frameworks, methods, tools and metrics to monitor and evaluate the efficiency as well as benefits of e-government investments are lacking. Above all, a clear understanding of the value of egovernment, and value for whom, is needed.

\section{Key research questions:}

- What frameworks, methods and metrics are needed to appropriately monitor, evaluate, and communicate the costs and benefits of ICT investments? Which tools are currently available and/or in development?

- What internal and external factors influence the value of e-government for different stakeholders?

- Whose and which values and indicators need to be assessed?

- How to ensure consideration of requirements and values of all stakeholders?

- Are methods such as value sensitive design (VSD) good enough to develop and support systems based on human values?

eParticipation, citizen engagement and democratic processes: In using ICT, elected officials and civil servants must remain open and accountable in their activities, behavior, and decision-making. At the same time, government must ensure that those individuals and groups that wish to participate in democratic processes have the opportunity and means to do so.

Key research questions:

- What are the social and technical dimensions of participatory democracy, and what are the barriers of low citizen engagement?

- How might citizens be better informed and involved in governmental decision-making processes?

- How might the health of democratic discourse be measured? And might democratic models change with a wide spread of eParticipation?

Mission-oriented goals and performance management: Many e-government projects do not start with the primary missions of government in mind. Instead, they are often dominated by a technology-driven approach. This is similar to the situation in which a budget is structured and evaluated by the nature of expenses rather than by the public service goals that expenditures support. In both cases management attention is diverted away from the core mission.

Key research questions: 
- How might a mission-oriented view of egovernment change priorities, investments, practices, and assessment of results?

- What are the deficiencies of present monitoring and controlling methods used at the various levels of governments in respect to budget planning and spending? How to evaluate the obstacles and barriers of change, including constraints introduced by organizational cultures?

- Which organizational and procedural performance management changes are required to implement mission-oriented e-government lined up with a proper planning, spending and controlling management (such as reward systems, laws and regulations)?

- Which peculiarities do proper resource planning information systems have implement in order to meet the needs of a mission-oriented goals and performance management in the public sector?

Cyber infrastructures for e-government: Future e-government technology platforms might consist of a reliable, ubiquitous infrastructure that supports systems and applications assembled out of readilyavailable, re-usable components. However, realization of this possibility requires research in various domains including whether and how a building block-oriented ICT-industry could develop, and what types of architectures, building blocks, and standards are needed.

Key research questions:

- Which elements make up and which conditions need to be fulfilled to enable the establishment of a pan-European cyber infrastructures and building block industry and technology platform?

- What would be the main products and contributions of such a technology industry for egovernment (standards, out-of-the-box modules, web services repository, etc.)? How (if at all!) can collaboration among all levels of government (horizontal and vertical collaboration) be facilitated and made interoperable in general with such a building blocks industry?

- Who should initiate such a building block infrastructure, which business models are feasible, and how to guarantee secure, reliable and reliable services for governments in a competitive market?

- What would be the conditions and incentives for creating a building block industry?

Ontologies and intelligent information and knowledge management: Governments are currently struggling with huge information overloads, with new and emerging ICT capabilities, and with a shortage of information management skills and human expertise. Ontologies and knowledge management facilities (such as search, retrieval, visualization, text mining, and intelligent reasoning) seem promising be exploited to achieve information quality and economy, and to support knowledge management processes in e-government settings.

\section{Key research questions:}

- How can ontologies and knowledge management facilities (such as search, retrieval, visualization, text mining, and intelligent reasoning) be exploited to achieve information quality and economy, and to support knowledge management processes in e-government settings?

- How to extract and retrieve information and valuable knowledge, as well as mining data and text from unstructured and dispersed knowledge bases and information sources?

- How to visualize knowledge and create cognitive knowledge models accessible for all, as well as intelligent interfaces for all?

- How to build a foundation of common reference models (ontology) for e-government and eParticipation?

- How do advanced information and knowledge management tools and concepts in e-government impact governments, market and society as well as information quality and information economy in respect to government activity?

Governance of public-private-civic sector relationships: Increasingly, governmental functions and public services incorporate significant roles for private sector or civic organizations. These roles play out in a variety of relationships from advisory, to collaborative, to contractual, to full partnerships. Adequate principles and frameworks are lacking, which facilitate and set the ground of collaboration in advancing and deploying e-government in regards to sharing responsibilities and exchanging information among networks of diverse organizations in ways that generate public value and satisfy public requirements for fairness, accountability, and competence.

Key research questions:

- What principles and frameworks are needed for sharing responsibilities and exchanging information among networks of diverse organizations in ways that generate public value in the e-government offers and that satisfy public requirements for fairness, accountability, and competence?

- Which State functions and tasks should be performed only by governments? 
- How to develop a legal framework and effective governance structures for cross-sector arrangements? And what policies and strategies are needed for ensuring integration and accountability of public services provided by organizations other than public bodes underlying strict legal obligations?

Government's role in the virtual world: Global electronic markets, virtual organizations, virtual identities, virtual products and services, and Internetrelated crime are growing in prominence and importance. In a world that is increasingly nonphysical and borderless, government's roles, responsibilities and limitations are subject to change and are blurring.

Key research questions:

- What are government's roles, responsibilities and limitations in a world that is increasingly non-physical and borderless?

- Is a different legislation needed for the cyberspace? What is needed if national laws are to be translated into the Internet, e.g. to generate virtual national borders or to set up global international legal framework? If new international laws are needed, who will define and who will implement the laws?

- Who will keep the legislators of international cyber laws under surveillance? Who could be in possession of the sovereign power? What will happen if only a few governments undertake efforts to strongly regulate the Internet?

- What kind of virtual citizenship will appear?

Crossing borders and the need for governance capabilities: The scope of problems and trends that governments need to cope with vary widely in size, intensity, and complexity. Social networks, gender issues, environmental concerns, political movements, etc. reach beyond local, regional or national borders. It is unclear, how these phenomena can be steered and governed properly across organizational boundaries, especially through exploiting capabilities available in neighborhood regions and contexts.

\section{Key research questions:}

- How can government support communication, action and services across traditional borders?

- What governance networks are needed in such diverse cultural / technical / political contexts within a large European Union with its rich societal diversity and internal market?

- How to steer governance networks properly? And what technical support will be needed to steer governance networks?

- Which kinds of human capabilities will be needed? e-government in the context of sociodemographic change: Demographic trends with global consequences (such as age distribution, wealth distribution, immigration, and mobility and distribution of workers) are generating pressing issues in both developed and developing countries. Within the European Union, facilitating mobility of citizens and trade across the whole internal European market are strategic aims to foster. These strategic goals as well as the demographic movements and changes require the public sector at the various administrative and political levels to act and react with according public service offers.

\section{Key research questions:}

- What opportunities and risks do these demographic movements imply for governments at the various administrative and political levels?

- What ICT and e-government services will be needed in such an environment?

- How to streamline fast adoption of the current public administration systems like taxation, social security, healthcare, etc. to a European model which meets the current needs of the demographic change?

- What technology solutions can help empower elderly people to stay connected with the world of cyberspace, and to benefit from enhanced services targeted towards elderly?

- What role does government have in managing the evolving competition for human resources among regions / nations and in ensuring an even development across regions and countries (including the aspect of government service quality as a competitive [dis]advantage factor)?

- How to ensure the successful integration of immigrants to the society of their chosen environment?

- What government services (and specific technology support) are needed to cope with new challenges due to climate change and other events mentioned in the scenarios.

Data privacy and personal identity: Data privacy and personal identity have become important aspects in the Information Society. On the one hand, the potential of modern ICT could be exploited to take advantage of personal information to improve the performance and quality of government services. On the other hand, privacy and personal data need to be secured and protected in order to prevent misuse and fraud.

Key research questions:

- What are the potential dangers and detailed characteristics for data misuse in a virtual world? 
- What policies, protocols, and data management mechanisms are needed to balance individual privacy protection with effective and efficient use of that information by government?

- And what technical means are required to assure that privacy and personal data are secured and protected, and will not be misused?

- How does e-government technology affect identity, self-reflection, self-awareness, and trust? And how much privacy are citizens willing to loose in order to get sophisticated government services?

- Is an implanted chip an unwanted future scenario, where preventive measures need to be taken now to streamline evolution in another direction? If so, which direction?

\section{Reflecting on the synthesis process of the roadmap themes}

The thirteen research themes were elaborated in several rounds of analysis and expert consultation. First, single regional workshops have been conducted (see Table 2), which resulted in a wide range of diverging research themes and trends. Then, the project members synthesized the results, grouped and merged similar themes, and eliminated redundancies. Furthermore, the research themes mostly linked to the gap storylines were condensed. This resulted in eight main research themes.

In a European-wide consultation workshop in the beginning of January 2007 (held in Brussels, BE), these eight research themes have been exposed to the assessment and discussion of 43 experts. These eight research themes were: Semantic and cultural interoperability; crossing borders and the need for governance capabilities; data privacy in egovernment service provision; fostering trust in egovernment; governance of public-private-civic sector relationships; Government's role in the virtual world; information quality in decision making; assessing the value of IT in government.

During this consultation workshop the eight research themes were extended to thirteen research themes discussed in the preceding section.

In total 11 regional roadmapping workshops were carried out in a short time-span of four months starting in October 2006 and ending in January 2007.

Table 2 also shows the overall participation of distinct target experts in the regional roadmapping workshops organized and an online consultation held.

These thirteen research themes have then been exposed again to a wide range of experts via the online consultation, with the aim to assess the importance of each single research theme. The results of this online survey are reported in [18].

The thirteen research themes interrelate with on another, i.e. many aspects are inextricably linked. This is not surprising as these interdependencies and mutually inclusive aspects were already identified in the gap analysis. They also result from the multidisciplinary understanding of e-government throughout the whole project.

Table 2: Number of participants per expert group in the regional workshops and the online consultation [19]

\begin{tabular}{|l|r|r|r|r|r|r|r|r|r|r|r|r|r|r|}
\cline { 2 - 16 } & \multicolumn{9}{c|}{} & \multicolumn{9}{c|}{ AT } & ES & IT & DE & NL & LT & SI & FR & US & BE & AU & Online & Total \\
\hline Government \& Politicians & 6 & 3 & 8 & 1 & 5 & 7 & 4 & 3 & & 14 & 6 & 14 & 71 \\
\hline IT Industry and Consulting & 5 & 12 & 1 & 8 & 7 & 6 & 8 & 2 & & 14 & 10 & 19 & 92 \\
\hline Academia & 5 & 13 & 4 & 9 & 5 & 6 & 6 & 7 & 20 & 15 & 12 & 75 & 177 \\
\hline Total & 16 & 28 & 13 & 18 & 17 & 19 & 18 & 12 & 20 & 43 & 28 & 108 & 340 \\
\hline
\end{tabular}

Legend: AT: Austria, ES: Spain, IT: Italy, DE: Germany, NL: The Netherlands, LT: Lithuania, SI: Slovenia, USA, BE: Belgium, AU: Australia

\section{Conclusions}

The results of the eGovRTD2020 project are overwhelming in the sense that a new research methodology has been developed and a large number of research themes have been identified. The need of multidisciplinary research has been expressed quite clearly in these research themes. However, research and implementation cultures yet have to adapt such a cross-disciplinary thinking. Dealing with the complexity of the field is also not an easy task in many e-government developments. As a consequence, focus is still put on single research disciplines.

In this paper we presented the roadmapping methodology and gave an overview of the results derived from using the roadmapping methodology. The unique characteristics of e-government, call for a roadmapping approach capturing the unique, idiosyncratic characteristics of e-government. Whereas roadmapping methodologies focus on technological products for satisfying customer needs, the 
eGovRTD2020 methodology deals with societal challenges to identify research needs. Moreover, the approach used a combination of workshops and online consultation to enable both in-depth interactions and discussions with a limited number of participants and to target a large audience representing countries worldwide.

With the 13 research themes, multidisciplinary research and implementation become obligatory. Yet, we do not have the right methods and tools available to address multidisciplinary themes and multidisciplinary areas of application.

The thirteen research themes and the roadmap resulting from the project activities are targeted for decision makers at the EU level, national level, ICT industry and consulting, as well as research. The eGovRTD2020 roadmap is a communication and awareness creation tool for relevant strategic decisionmakers responsible for advancing society, government and industry developments. The aim of creating awareness of the need for further research was demonstrated through the high participation of experts from the different fields in the workshops.

The results of the eGovRTD2020 project provide a baseline of argumentation for strategic decisionmakers in government, politics, and the ICT industry and consulting to direct research efforts towards important new challenges. The project results offer several future visions and concrete e-government research actions linked to advanced solutions in this field. The 13 research themes help build a baseline for the next calls of the $7^{\text {th }}$ Framework Program of the European Commission with respect to e-government research themes and priorities. They also provide a guide for national research programs to support innovative RTD for public sector responsibilities and to spur innovation emerging from within the public sector in order to contribute to a highly innovative knowledge society.

\section{Acknowledgement}

This paper is based on research within the eGovRTD2020 (Roadmapping eGovernment research 2020, IST-2004-4-27139) project, a specific support action co-funded by the European Commission under the 6th framework program of IST. More information can be found at http://www.egovrtd2020.org.

\section{References}

[1] Bicking, M., Janssen, M. \& Wimmer, M.A. Looking into the future: Scenarios for e-government in 2020. In Sixth IFIP conference on e-Commerce, e-Business, and
eGovernment (I3E 2006), Project E-Society: Building Bricks, Springer Verlag, October 11-13, 2006, Turku, Finland. pp 392-404.

[2] Codagnone, C. \& Boccardelli, P. Measurement Framework Final Version, eGovernment Economics Project, Rome: eGEP Consortium, 2006, retrieved from http://82.187.13.175/eGEP/Static/Contents/final/

D.2.4_Measurement_Framework_final_version.pdf.

[3] Codagnone, C., Caldarelli, L., Cilli, V., Galasso, G. \& Zanchi, F. Compendium to the Measurement Framework, eGovernment Economics Project, Rome: eGEP Consortium, 2006, retrieved April 2007, from http://217.59.60.50/eGEP/Static/Contents/ final/Measurement_Framework_Compendium.pdf.

[4] Codagnone, C. \& Wimmer, M.A. (eds.). Roadmapping eGovernment Research: Visions and Measures towards Innovative Governments in 2020. MY Print snc di Guerinoni Marco \& C, Clusone, 2007

[5] Corsi, M., Gumina, A. \& D'Ippoliti, C. Economic Model Final Version, eGovernment Economics Project, Rome: eGEP Consortium, 2006. Retrieved April 2007 from http://82.187.13.175/eGEP/Static/Contents/final/D.3.3_ Economic_Model_Final_Version.pdf

[6] EC Staff Working Paper. European Competitiveness Report 2004. SEC (2004) 1397. Retrieved from $\mathrm{http}$ //europa.eu.int/comm/enterprise/enterprise_policy/ competitiveness/doc/comprep_2004_en.pdf

[7] European Commission. i2010 - A European Information Society for growth and employment, $\operatorname{COM}(2005) 229$ final. Brussels.

[8] European Council. Presidency Conclusion of the Lisbon European Council (23-24 March 2000). Lisbon.

[9] Grossman, D.S. "Putting technology on the road," Research Technology Management, vol. 47, 2004, pp. 41-46.

[10] Janssen, M., Duin, P. van der, Wagenaar, R.W., Bicking, M., Wimmer, M.A., Sharon, D. \& Petrauskas, R. Scenario building for E-Government in 2020: Consolidating the results from regional workshops. In: Proceeding of the Hawaii International Conference on System Sciences (HICSS-40), IEEE, 2007.

[11] Janssen, M., Wimmer, M.A., Bicking, M. \& Wagenaar, R. Scenarios of governments in 2020. In: [4], 2007, pp. 55-84.

[12] OECD. Engaging Citizens in Policy-making: Information, Consultation and Public Participation. OECD Public Management Policy Brief, 2007, retrieved April 2007 from https://www.oecd.org/dataoecd/24/34/2384040.pdf.

[13] Phaal, R., Farrukh, C.J.P. \& Probert, D.R. "Technology roadmapping - A planning framework for evolution and revolution," Technological Forecasting \& Social Change, vol. 71, 2004, pp. 5-26.

[14] Probert, D. \& Shehabuddeen, N. "Technology roadmapping: the issues of managing technology 
change," International Journal of Technology Management, vol. 17, 1999, pp. 646-661.

[15] Pucihar, A., Bogataj, K., Wimmer, M.A., Janssen, M., Malinauskiene, E., Bicking, M., Petrauskas, R., Klein, M., Ma, X., Amadori, G. \& Traunmüller, R. Gap analysis: the process and gap storylines. In: [4], 2007, pp. 85-120.

[16] Wimmer, M.A. "Integrated service modeling for online one-stop Government", EM - Electronic Markets, special issue on e-Government, Vol. 12, No. 3, 2002 pp. 1-8.

[17] Wimmer, M.A. The Role of Research in Successful EGovernment Implementation. In: Zechner, A. (Ed.) EGovernment Guide Germany. Strategies, Solutions and Efficiency. Stuttgart, Fraunhofer IRB Verlag, 2007, pp. 79-87.
[18] Wimmer, M.A. Roadmap for future research and implementations in eGovernment: Reflecting the synthesis process of the roadmap themes. In: [4], pp. 148-149.

[19] Wimmer, M.A., Bicking, M., Bogataj, K., Bowern, M., Codagnone, C., Dawes, S.S., Janssen, M., Klein, M., Ma, X., Malinauskiene, E. \& Pucihar, A. Roadmap for future research and implementations in eGovernment: Research themes and roadmap charts. In: [4], 2007, pp. 123-148.

[20] Wimmer M.A., Codagnone, C. \& Ma, X. Developing an eGovernment research roadmap: Method and example from eGovRTD2020. In: Wimmer, M.A., Scholl, H.J., Grönlund, A. (eds). Electronic Government. Proceedings of EGOV 07. LNCS \# 4656, Springer Verlag, Berlin et al, September 2007, pp. 1-12. 